\title{
A study on pattern of lower respiratory tract infections in children below 12 years of age admitted to KIMS hospital, amalapuram.
}

\author{
Ramesh T. ${ }^{1 *}$, Naveen Kanth N. ${ }^{2}$, Swagath M. ${ }^{3}$ \\ DOI: https://doi.org/10.17511/ijpr.2021.i01.01
}

\author{
1* T.V. Ramesh, Professor \& Head, Department of Paediatrics, Konaseema Institute of Medical Sciences \& Research Foundation, \\ Amalapuram, Andhra Pradesh, India. \\ 2 Nadakuditi Naveen Kanth, Resident, Department of Paediatrics, Konaseema Institute of Medical Sciences \& Research Foundation, \\ Amalapuram, Andhra Pradesh, India. \\ 3 Swagath M, Resident, Department of Paediatrics, Konaseema Institute of Medical Sciences \& Research Foundation, Amalapuram, Andhra \\ Pradesh, India.
}

Background: Acute respiratory infections (ARI) in children less than five years are the leading causes of mortality. A study was conducted to know the incidence of different types of LRTIs and the common causative organisms. Methods: Routine investigations were carried out on 824 hospitalized children over 18 months and with special investigations like X-ray chest, USG chest, blood culture, pleural fluid analysis, tuberculin skin test, and CBNAAT for tuberculosis.the data were analyzed. Results: Out of 100 cases, 2 cases were diagnosed as tuberculosis. Others, i.e., 97 improved and discharged. The minimum hospital stay was 3 days, and the maximum was 21 days. The incidence of LRTI in children was maximum (48\%) in 1 - 4 years age and Protein-energy malnutrition (PEM ) was detected in $72 \%$ children. PEM I was maximum (35\%) followed by PEM II (16\%), PEM III (12\%) and PEM IV (9\%. Bronchopneumonia was diagnosed maximum (52\%) followed by bronchiolitis (12\%). Mantoux test was positive in $21 \%$. Staphylococcus aureus was isolated maximum and no significant drug resistance was identified. Conclusion: Maximum incidence of LRTIs were detected between the age group of 1 - 4 years, malnutrition was an associated factor.

Keywords: Report, Infection, Respiratory Tract, Pneumonia

\section{Corresponding Author}

T.V. Ramesh, Professor \& Head, Department of Paediatrics, Konaseema Institute of Medical Sciences \& Research Foundation, Amalapuram, Andhra Pradesh, India. Email: drtvr2010@gmail.com

\section{How to Cite this Article}

Ramesh TV, Kanth NN, Swagath M. A study on pattern of lower respiratory tract infections in children below 12 years of age admitted to KIMS hospital, amalapuram.. Pediatric Rev Int J Pediatr Res. $2021 ; 8(1): 01-06$.

Available From

https://pediatrics.medresearch.in/index.php/ijpr/arti cle/view/657
To Browse

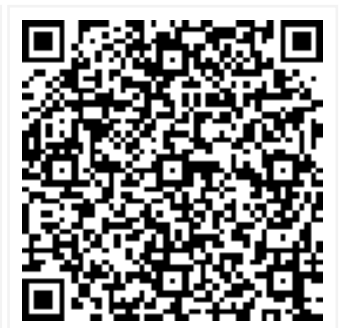

Manuscript Received 2021-01-25

Conflict of Interest No

Review Round 1
2021-02-05
Funding
Nil

Review Round 1 $\mathrm{Nil}$

Review Round 2
2021-02-10
Ethical Approval
Yes

Review Round 3

Plagiarism X-checker $7 \%$
Accepted 2021-02-15

Note 


\section{Background}

Acute respiratory tract infections (RTIs) are one of the leading causes of morbidity and mortality among children. WHO estimated the burden of RTIs in 2010, estimates four and half million deaths due to RTIs among children every year. In India, 1.2 million deaths have reported among children due to RTI among 5.9 million deaths globally [1].

India has the highest number of deaths among children $<5$ years of age and most of them are due to respiratory tract infections (LRTIs). These infections are broadly divided into upper and lower respiratory tract infections. LRTIs are the most common causes of death, pneumonia and bronchiolitis are the commonest, accounts for most of the deaths in children $<5$ years [2].

LRTI is not a single disease entity, but a group of infections with different etiology, risk factors, pathogenesis, clinical presentations, and outcomes. The etiology, epidemiology, and symptomatology vary with age, gender, risk factors, season, place, and type of population. These LRTI are affected by socio-demographic and Socio-cultural factors, which are modifiable by simple interventional measures [3].

Modifiable risk factors were lack of breastfeeding, overcrowding, undernutrition, delayed weaning, and pre lacteal feeding. Other associated conditions like PEM, infectious diseases, and secondary bacterial infections make the child more vulnerable to mortality and morbidity. The etiological agents of LRTI are viral, bacterial in origin or both together [4]. With these, study was conducted to evaluate to find various LRTIs in children below 5 years age.

\section{Methods}

Study design: It was a cross sectional, time bound study.

Study population: Study consisted of children aged $\leq 5$ years.

Study setting: Study was conducted in the department of pediatrics, Konaseema Institute of Medical Sciences (KIMS), Amalauram.

Ethical approval: The study protocol was approved by the institutional ethical committee

Study period: Study was conducted from January 2018 to June 2019,18 months.
Inclusion criteria: in this study, children admitted with the symptoms of fever, cough, breathlessness, wheeze, stridor, chest pain were included.

Exclusion criteria: Neonates less than 1 month of age, those who were not submitted informed written consent were excluded.

Sample size: This was a time bound study, hence all the members who satisfied the inclusion criteria were considered, total 100 members were considered.

History and clinical examination on the admission of each child was recorded. In history, symptoms like cough, breathlessness, fever and pain in the chest, history of repeated RTIs, history of skin infection, or any infective lesions over the body asked. Past and family history carefully recorded with more emphasis on the history of contact with tuberculosis. History of immunization regarding BCG, polio, pentavalent, and measles/MR, special vaccines recorded. A thorough clinical examination of the systems was carried with more emphasis on the respiratory system. Signs like cyanosis, clubbing, lymphadenopathy, pallor, and any infective foci over the body made the appearance of new signs and symptoms carefully recorded.

Routine investigations such as $\mathrm{Hb} \%$, total, differential leukocyte count and ESR were carried out in the laboratory immediately after an admission. Special investigations like lumbar puncture and ECG done wherever necessary, x-ray chest done in all the 100 cases after admission. Chest $X$ ray was repeated in some of the cases after clinical deterioration, and compared with an $\mathrm{X}$ ray was taken at admission, Mantoux (TST) was done to all. Throat swab, sputum (if productive) for acid-fast bacilli (AFB), culture sensitivity and gram stain were done. In non-productive cough and in infants who do not bring out the sputum gastric aspiration was done, and stained for AFB and sent for CBNAAT.

Pleural tapping was done, where ever clinically pleural effusion, empyema suspected. The aspirated fluid was analyzed for type of cells, gram staining, culture sensitivity, AFB and other biochemical investigations like protein and sugar estimation and cytology.

\section{Results}

The incidence of LRTI in children was maximum $(48 \%)$ between $1-4$ years. Followed by $<1$ year (22\%), $5-8$ years (18\%) and $9-12$ years (12\%) 
(Table 1). Gender wise, $57 \%$ were male members and the male female ratio was 1.3 . Total $65 \%$ were belong to the low socioeconomic groups with family income ranged between Rs. 1500 to 2000 per month.

In this study, $72 \%$ children were associated with PEM, which predominantly observed in serious diseases like Empyema and pneumonia. The incidence PEM was highest (35\%) in grade I PEM followed by PEM II $(16 \%)$, PEM III (12\%) and PEM IV $(9 \%)$. Serious illness was noted in PEM grade-III and IV.

BCG was administered to $86 \%$, DPT/pentavalent, polio (oral polio vaccine/IPV) and measles was received by $84 \%$ respectively. Grade wise, PEM I was maximum (35\%) followed by PEM II (16\%), PEM III (12\%) and PEM IV (9\%) (Table 3).

In this study, bronchopneumonia was diagnosed maximum (52\%) followed by bronchiolitis (12\%), pneumonic consolidation of lung $(8 \%)$, acute laryngotracheobronchitis and pleural effusion (6\% each). Nearly, $6 \%$ of children had severe anemia ( $\leq$ $5 \mathrm{gms})$, mild to moderate degree anemia (5 - 10 gms) in $56 \%$. Normal levels of hemoglobin was diagnosed in $38 \%$.

Out of a total of 100 cases, $21 \%$ positive Mantoux test. In these, 11 had immunized with BCG vaccination during infancy and 1 was positive HIV serology (Table 4). Unilateral pulmonary infiltration in $42 \%, 18 \%$ had bilateral pulmonary infiltration, $9 \%$ had pleural effusion and empyema, $1 \%$ had bilateral pleural effusion with pericardial effusion.

Out of 6 cases of straw-colored fluid, 2 cases yielded growth, and others are sterile. Out of two cultures, positives organisms grown are 1 case was Klebsiella pneumonia, and 1 case of streptococci. Klebsiella species, Staphylococcus aureus was isolated in 4 each members respectively, Streptococcus in 5 and Coagulase negative staphylococcus in, total 14 isolations.

Table1: Age wise distribution of the study members.

\begin{tabular}{|l|l|l|}
\hline \multicolumn{1}{|c|}{ Age in years } & \multicolumn{1}{c|}{ Number } & \multicolumn{1}{c|}{ Percentage } \\
\hline$<1$ & 22 & 22 \\
\hline $1-4$ & 48 & 48 \\
\hline $5-8$ & 18 & 18 \\
\hline $9-12$ & 12 & 12 \\
\hline Total & 100 & 100 \\
\hline
\end{tabular}

Table 2: Gender wise distribution of study members.

\begin{tabular}{|l|l|l|}
\hline \multicolumn{1}{|c|}{ Gender } & \multicolumn{1}{c|}{ Number } & \multicolumn{1}{c|}{ Percentage } \\
\hline Female & 43 & 43 \\
\hline Male & 57 & 57 \\
\hline Total & 100 & 100 \\
\hline
\end{tabular}

Table 3: Association of Protein-energy malnutrition (PEM) in the study team.

\begin{tabular}{|l|l|l|}
\hline \multicolumn{1}{|c|}{ Grading of PEM } & Number & Percentage \\
\hline Normal & 28 & 28 \\
\hline PEM-I & 35 & 35 \\
\hline PEM-II & 16 & 16 \\
\hline PEM-III & 12 & 12 \\
\hline PEM-IV & 9 & 9 \\
\hline Total & 100 & 100 \\
\hline
\end{tabular}

Table 4: TST/Mantoux test results in the study members

\begin{tabular}{|l|l|l|}
\hline \multicolumn{1}{|c|}{ Result } & \multicolumn{1}{c|}{ Number } & \multicolumn{1}{c|}{ Percentage } \\
\hline Positive & 21 & 21 \\
\hline Negative & 79 & 79 \\
\hline
\end{tabular}

\section{Discussion}

Children admitted with respiratory symptoms, and definite clinical signs included in this study, in this study, total $12.1 \%$ of the admitted patients had LRTIs. Munagala VK et al. reported that LRTI disorders in children accounted for $9.76 \%$ of the total of 375 children enrolled [5]. Bikash Gairola et al. reported that LRTI disorders in children accounted for $11.16 \%$, and URTI accounted for $88.84 \%$ of total ARI [6] and it was reported to be $27 \%$ by Sharma D, Kuppuswamy K [7]. The incidence appears to be high in our study. When compared with other studies. Probably because of the criteria for selection of cases, definitive clinical signs on examination. Gender wise, the male female ratio in this study was $1.33: 1,57$ cases were boys, and 43 were girls, which accounts to $1.33: 1$ ratio of sex incidence which falls in between sex incidences of many other studies, which ranged from $1: 1$ to 1.9:1. Almost similar results were reported by Peter D. Phelan et al [8], Paramesh $\mathrm{H}$ et al [9] and Lakhani JK et al [10] But the ratio was mentioned to be $2: 1$ in Munagala VK et al study [5]. This difference can be explained based on selection criteria and demography that is different in the above studies. Boys under the age of 6 years have a substantially higher incidence of LRTIS, but over the age of 6 years, the rates for boys and girls approximate each other. 
$74 \%$ of asthma attacks experienced in children less than five years of age and $26 \%$ in less than 1 year of age male to female ratio was $2: 1$. Male children tend to suffer more since they have smaller airways for a given lung size, which independently inherited in addition to the fact that boys have a higher incidence of LRTI during childhood.

In the present study, high incidence of LRTI was found in the age group between $1-4$ years (48\%). Approximately $70 \%$ of children belonged to the preschool age group. Whereas it wa reported that $63.84 \%$ of LRTIs in $1-5$ years age group [11].

In another Indian study by S.K.Kabra et al., 200 children below 5 years of age with a diagnosis of acute LRTIs was studied over 2 years and the authors reported there was no difference in age and gender distribution between the two groups [12]. In the present study, a higher incidence of LRTIs were found in the age group $1-4$ years, while broncho pneumonia less than 2 years of age.

This high incidence of LRTI is probably due relative airway diameter: Small airway constitutes about $80 \%$ of all airways in the infant. The small to large airway ratio, which is about four at birth, reduces to 0.25 by the age of 6 years. The small airways due to their size and fragility are most susceptible to mucous plugging and pathological damage. This probably important factor in the high incidence of respiratory distress among infants and early childhood.

The crucial period of health and development is directly proportional to its proper nutrition while in the mother's womb. Improvement in the nutritional status is vital as under nutrition was the underlying cause of almost half of child deaths, the majority (60 - 70\%) of cases of PEM and $2-5 \%$ suffer from severe malnutrition. The most common age of occurrence of PEM is six months to 2 years.

Around $50-60 \%$ of children are malnourished by the age of 2 years (National Family Health Survey). Malnutrion was mentioned to be $54.3 \%$ by Yellanthoor et al study [13]. In this study, nutrition played a significant role as predisposing factor for RTIs as $72 \%$ of children undernourished. Grade-I observed in $35 \%$, Grade-II in $16 \%$, and $12 \%$ of children had grade-III and $9 \%$ had grade IV protein-energy malnutrition.

Grade I showed a high incidence of LRTI, and III and IV showed high morbidity as prolonged hospital stay in our study. Munagala VK et al. reported that
$90 \%$ children were malnourished, grade I detected in $35 \%$, grade II in $22 \%$, grade-III in $17 \%$ and Grade IV in 14\%, and high incidence of LRTIs was detected in PEM grade I. 5 Gunnar et al. reported that out of 206 children below 5 years, $45.1 \%$ were mild malnutrition and $54.9 \%$ were moderate to severely malnourished and prevalence were same in the gender [14].

In the present study, $86 \%$ had BCG vaccination. $84 \%$ of children had Pentavalent/DPT, $86 \%$ had polio vaccination, and $84 \%$ had measles/MR vaccination. Similar data was also reported in another study which was conducted in this state. 5 Severity and transmissibility of RTIs by major pathogens, limited availability of laboratory diagnostics, makes vaccines as the best choice of intervention against ARI. Pneumonia is the most common cause of death due to measles in immunocompromised children; it accounts for up to $58 \%$.

Measles associated with severe pneumonia carries more than twice the risk of mortality than severe pneumonia in children without measles does, because pneumonia has a central role in measlesrelated mortality [15]. In the present study, the measles vaccine not received by 16 children, and out of the ten children had a history of measles associated LRTI in history, and measles was the contributing factor for respiratory infection for 2 cases in present admission.

Out of 100 children in this study, 65 children belong to the lower class as per the modified kuppuswamy scale. Twenty-five children belong to the middle socio-economic class, and ten children belong to the upper socio-economic class, which shows that LRTI incidence is more in Lower socioeconomic class. Yellanthoor R B et al. reported that in their study, $84.5 \%$ of children were in low socioeconomic category and the remaining $15.5 \%(32 / 206)$ had upper or middle socioeconomic status [13].

Munagala VK et al. reported that $73.6 \%$ of children in the low-income group, $16.3 \%$ in the middleincome group, and $10.1 \%$ in the high-income group [5]. All three studies reported that most of the children 70 - $80 \%$ belong to the lower socioeconomic class. Malnourished are more prone to ARI and progresses to LRTI with increased morbidity and mortality.

Among the study members, 62 were exclusively breastfed, 22 were mixed on feeding and 16 were completely on formula-fed. 
Not breastfed babies' history showed higher hospital visits due to ARI and Diarrhoea. Studies reported that breast feeding may enhance the antibody response to important pneumonia-causing pathogens. [16]. PROBIT, a large clusterrandomized trial of breastfeeding promotion based on WHO baby-friendly hospital initiative in Belarus, showed that there would be about a $40 \%$ reduction in diarrhea incidence and a $15 \%$ decrease in respiratory disease-related hospitalizations probably ALRTI [17].

A recent study conducted in India reported that $64.5 \%$ children were anemic; this was $62 \%$ in this study [18]. Ramakrishnan et al. found $74 \%$ of the cases anemic, while only $33 \%$ of the controls were anemic, which included children from 9 months to 16 years was showing maximum incidence in the children below six years [19]. No significant drug resistance was reported in this study, However similar findings were available in the literature.

\section{What this study adds to the existing knowledge}

Maximum incidence of LRTIs were detected between the age group of $1-4$ years, malnutrition was an associated factor.

\section{Author's contribution}

01. V. Ramesh: Article writing, study design.

02. Nadakuditi Naveen Kanth: Reference
collection, data analysis

03. Swagath $\mathbf{M}$ : data analysis

\section{Reference}

01. WHO. World health organization pneumonia. 2012. Available from http://www. who.Int/medicalcentre/factsheets/em/ [Crossref]

02. Francis BV, Abhilash TG. Study of acute respiratory tract infections in children. Internat J Sci Res. 2016;5(9)1791-2.

doi: 10.18203/2349-3291.ijcp20173775 [Crossref]

03. Alter SJ, Vidwan NK, Sobande PO, Omoloja A, Bennett JS. Common childhood bacterial infections. Current Probl Pediatric Adolescent Health Care. $2011 ; 41 ; 256-83$.

[Crossref]
04. Erling V, Jalil F, Hanson LA, Zaman S. The impact of climate on the prevalence of respiratory tract infection in early childhood in Lahore, Pakistan. J PubHealth. 1999;21;331-9. DOI: $10.1093 /$ pubmed/21.3.331 [Crossref]

05. Munagala VK, Mahesh RMU, Kanda J, Ponugoti M. Clinical study of lower respiratory tract infections in children attending a tertiary care hospital. Int J Contemp Pediatr. 2017;4;1733-8. doi: 10.18203/2349-3291.ijcp20180535 [Crossref]

06. Bikash, Devasri C, Daisy P, Deka A. Drug prescribing pattern in the respiratory tract infection in children aged 1 to 12 years at the outpatient department at Silchar medical college and hospital, Assam. Ind J pharm Biomed Sci. 2016;06;537-45.

[Crossref]

07. Sharma D, Kuppuswamy K, Bhoorasamy A. Prevalence of the acute respiratory tract Infections(ARI) and their determinants in under 5 children in urban and rural areas of Kancheepuram district, south India. Ann Troup Med public health. $2013 ; 6 ; 513-8$.

Available at: [Article] [Crossref]

08. Peter D Phelan, Anthony Olin sky, Colin F, Robertson. The epidemiology of Acute respiratory infections- Textbook of pediatrics on "Respiratory illness in children. "Blackwell Scientific Publications, 4th Edition. 1994;27-42. [Crossref]

09. Paramesh H. Epidemiology of asthma in children in India. Ind J Of pediatrics. $2002 ; 69 ; 309-12$. doi: $10.1007 /$ BF02723216 [Crossref]

10. Lakhani JK, Sanjeev Joshi. Intercostal tubedrainage practical tips. Karnataka Pediatric J. $2004 ; 18 ; 14-16$. doi: $10.1055 / \mathrm{s}-0029-1208074$ [Crossref]

11. Paul LMcCarthy, Sydney Z Spiesel Carole, Stashwick A, Ronald C Ablow, Stuart J Masters, Thomas $F$ Dolan Jr. Radiographic findings and etiologic diagnosis in ambulatory childhood pneumonia. Clin Pediatrics. $1981 ; 20 ; 686-91$.

doi: $\quad 10.1177 / 000992288102001101 \quad$ [Crossref] 
12. Kabra SK, Broor S, Rakesh Lodha, Maitreyi RS, Ghosh M, Pandey RM, Puranik M. Brief reports can we identify acute severe viral lower respiratory tract infection clinically?. Ind Pediatrics. $2004 ; 41 ; 245-9$.

[Article] [Crossref]

13. Yellanthoor $R$ B, Shah V K B. prevalence of malnutrition among under five year old children with acute lower respiratory tract infection hospitalized at Udupi district hospital. Arch pediatric infectious disease. $2014 ; 2(2) 203-6$.

DOI : 10.5812/pedinfect.14373 [Crossref]

14. Gunnar D Stickler, Alan D Hoffman, William F Taylor. Problemsinthe clinical and roentgenographic diagnosis of pneumonia in young children. Clin Pediatrics. 1984;23;398399.

doi: $10.1177 / 000992288402300707$ [Crossref]

15. Kumar KGR, Sameer Bakshi, Samantaray JC, Banerjee UanArya LS. Trans thoraciclungaspirationin theetiology of pneumonia. Ind J Of Pediatrics. 2004;71;12932.

DOI: [Article] [Crossref]

16. Black RE, Allen LH, Bhutta ZA, Caulfield LE, de Onis M,Ezzati M, et al. Maternal And child under nutrition- global and regional exposures and health consequences. Lancet. 2008;371;24360.

doi: $10.1016 / \mathrm{S} 0140-6736(07) 61690$ [Crossref]
17. Daniel E Roth, Laura E Caulfield Majid Ezzati Robert E Black. WHO/ Acute lower respiratory infections in children- opportunities for reducing the global burden through nutritional interventions who bulletin. Bull World Health Organ. $2019 ; 11 ; 4$.

doi: $10.2471 /$ blt.07.049114 [Crossref]

18. Awasthi S, Ektakalra, Roy S, Awasthi S. Prevalence and Risk-Factors of Asthma and Wheeze in School going childrenin Lucknow. Ind Peditrics. 2014;41;1205-9.

[Article] [Crossref]

19. K Ramakrishnan P, S harish. Study on various lower respiratory tract infections in school going children. The Ind J Of Pediatrics. 2006;73;88188.

DOI: 10.18203/2349-3291.ijcp20173775 [Crossref]

20. Saket Kumar, Shally Awasthi, Amita Jain, Srivastava RC. Blood zinc levels in children hospitalized with severe pneumonia - A casecontrol study. Ind Pediatrics. $2004 ; 41 ; 486-90$. [Crossref] 